\title{
A contribuição do jornalismo para as crônicas de Clarice Lispector
}

The contribution of journalism for Clarice Lispector chronicles

\author{
IVANA Mendes CaRdoso BarReto \\ Graduada em Comunicação Social (habilitação jornalismo) pela PUC-RJ; Pós-graduada em \\ Literatura Brasileira pela UERJ; Mestre em Literatura Brasileira pela UFRJ; Doutora em Literatura \\ Brasileira pela PUC-RJ. \\ E-mail: ivanabarreto@superig.com.br
}

\section{Resumo}

0 objeto de estudo deste trabalho são os textos de Clarice Lispector produzidos para o Caderno B do Jornal do Brasil, no período de 1967 a 1973, e o inegável arejamento que eles adquiriram ao serem publicados na mídia impressa, possibilitando à autora uma maior aproximação com seu público leitor. Por outro lado, mesmo aqueles que não eram leitores de sua obra, considerada por muitos de difíicl acesso, puderam trocar experiências com a autora, a partir de textos que, no espaço jornalístico, ganhavam em brevidade e objetividade, características que facilitam sua leitura pelos leitores de jornais.

Palavras-chave: Jornal do Brasil, crônicas, Clarice Lispector.

Entre os anos de 1967 e 1973, uma das maiores escritoras da Língua Portuguesa, Clarice Lispector, contribuiu, semanalmente, para o Caderno B do Jornal do Brasil. Escreveu uma coluna, que obteve grande repercussão e possibilitou que a autora se aproximasse mais de seus leitores. Mérito de Clarice e, inegavelmente, do $J b$, na época, um veículo revolucionário, tanto na forma - com sua inovação na linguagem visual - como no conteúdo. Afinal, grandes escritores contribuíam para o Caderno B, como Carlos Drummond de Andrade, apenas para citar um deles. No espaço jornalístico, os textos da autora encontraram um arejamento, que ampliou sua relação com seu público leitor. Obviamente, ao escrever para o jornal, ela, na maioria das vezes, elaborava pequenas introduções, que davam um tom mais direto ao conteúdo que vinha a seguir.

Além disso, embora aproveitasse vários trechos de livros já publicados (ou não), retirava destes somente o que lhe interessava tratar no diálogo que travava com seus leitores. Isso porque, no espaço jornalístico, especificamente na mídia impressa, no caso aqui analisado, a objetividade e a brevidade são fundamentais, o que já não acontece na literatura. Pelo contrário. Enquanto em seus romances ela podia ocupar cinco páginas para descrever um personagem, na coluna do JB esse espaço já não poderia ser o mesmo. No máximo, e era o que acontecia em muitas ocasiões, Clarice interrompia a coluna num determinado ponto e comunicava ao leitor que a retomaria na próxima semana.

Como o objeto de estudo deste trabalho são os textos de Clarice Lispector produzidos para o Jornal do Brasil, e o inegável arejamento que estes mesmos textos adquiriram ao serem publicados na mídia impressa, a linha de interpretação desenvolvida implicará em privilegiar a abordagem do efeito recíproco autor/leitor, afastando-se do interesse 
pelos procedimentos da narrativa que privilegia estruturas e técnicas da escrita bastante exauridas pelo modelo analítico. $\mathrm{Na}$ linha de interpretação eleita, o sistema narrativo, ao invés de ser percebido como autônomo, será analisado em sua relação com o leitor.

Antes, porém, faz-se pertinente ressaltar a questão da linguagem, que se interpõe entre o autor e sua obra, estabelecendo uma relação ambígua, desvelamento e obstáculo à comunicação da subjetividade autoral e que vem a ser suporte para o diálogo com o leitor, isto é, o texto desta obra.

A leitura das crônicas de Clarice Lispector e de seu jogo com o outro adotará a figura do leitor real, como foi sugerida por Michel Picard nos ensaios "A leitura como jogo" (1986) e "Ler o tempo" (1989). Aqui, estamos diante do encontro com o leitor real, de carne e osso, que semanalmente abria, lia, dobrava, carregava consigo o suplemento literário do JB e entre cartas mencionadas nas crônicas se imiscuía na vida/obra da autora. Esta posição de Picard nega o leitor desencarnado dos modelos de Iser e Eco e, apesar das diferenças que mantêm umas com as outras, o paradigma destas teorias é o da recepção, transformando o leitor em sujeito ativo de um processo que se abre para muitas interpretações.

É inegável o arejamento, como já mencionado, que os textos de Clarice Lispector adquiriram ao serem publicados no Jornal do Brasil. Comparando-os com trechos idênticos ou quase idênticos de romances da autora, convém, contudo, melhor caracterizá-los. Fragmentos pessoais e íntimos, distantes da crônica de costumes que habitualmente preside o gênero. Era este o perfil dos textos da "cronista" Clarice Lispector, escritos entre agosto de 1967 e dezembro de 1973, posteriormente reunidos no volume A descoberta do mundo. Publicados aos sábados, eles eram a tradução confessional de seus impulsos e experiências de vida. Como ressalta Lícia Manzo, em Era uma vez: eu, já em 22 de novembro de 1969, Clarice afirma: "só sei ser íntima”. (MANZO, 2001, p. 87)

Já remontando às considerações de Marina Colasanti, subeditora do Caderno B do Jornal do Brasil no citado período, convém lembrar que, convidada em 1967 para escrever semanalmente no JB, Clarice se deparou com um fazer literário novo. Intimidada, num primeiro momento, logo negou os padrões vigentes. Em A descoberta do mundo, registra, em "Máquina escrevendo":

Vamos falar a verdade: isto aqui não é crônica coisa nenhuma. Isto é apenas. Não entra em gêneros não me interessam mais (LISPECTOR, 199, p. 542).

Como era de sua natureza inquieta, sem querer deixar-se aprisionar em um gênero específico, Clarice, na verdade, ainda segundo Marina Colasanti, escreveu contos, que poderiam ser crônicas, que poderiam ser textos. Textos que espelhavam sua escrita ímpar, porque intensa e fragmentada. Por isso, este estudo chama primordialmente "textos" o material publicado no Jornal do Brasil, uma vez que sua classificação seria uma forma de diminuir sua força, abrangência e complexidade.

Afinal, as crônicas poderiam ser, no caso de Clarice Lispector, contos ou trechos de romances de alguém que pretendia não se deixar decifrar diante das pessoas, diante dos críticos.

Mas por que a polêmica se os textos do JB seriam ou não crônicas? Situada entre o jornalismo e a literatura, a crônica é quase 
sempre um texto curto e narrado em primeira pessoa, vale dizer, em que o escritor assume dialogar com o leitor. Remontando à trajetória desse gênero entre nós, a crônica brasileira foi aos poucos se afastando daquela de sentido documental originada na França e passou a ter um caráter mais literário, utilizando uma linguagem mais leve e envolvendo poesia, lirismo e fantasia, provocada por acontecimento muitas vezes banal, mas tocante para o escritor.

Rubem Braga, mestre do gênero, citando nomes contemporâneos de Clarice, recriou a narrativa com seu estilo de tomar flagrantes quase inexpressivos e iluminá-los.

Nesta esteira estavam Cecília Meireles, Carlos Drummond de Andrade e a própria Clarice.

As crônicas, sem dúvida, constituem parte importante da literatura brasileira. Podem, no entanto, traduzir-se em um instante de devaneio poético, filosófico e até mesmo irônico de autores pressionados pelo tempo corrido do relógio. Neste sentido, podem revelar traços novos, não antes vislumbrados, de seus autores. Um bom exemplo foi Carlos Drummond de Andrade, que enveredou por sátiras sutis à sociedade de seu tempo.

No caso de Clarice Lispector, os textos publicados na coluna semanal do $J B$ prolongaram e ampliaram seu auto-retrato, porque, embora breves na sua estrutura, estes textos/ crônicas/contos promoveram o aprofundamento de um momento complexo, de seu sentimento de humanidade, de um questionamento da existência. Além disso, não se pode esquecer que a crônica - e foi este o caso de Clarice - sempre divulgou, através de um meio de comunicação de massa mais barato e acessível do que o livro, o mundo dos autores e suas posições, opiniões, afetos. Especificamente tratando de
Clarice Lispector, pode-se entender que até com os leitores que nunca leram um de seus livros foi estabelecido um contato democrático.

Para os críticos, torna-se problemático classificar os textos escritos por Clarice Lispector, nem é prudente forçar uma obra a se enquadrar nos quadros de classificações teóricas. Pelo contrário, é preciso entender, neste caso, que a autora trabalhou com tanta liberdade seus textos que um trecho de crônica pôde aparecer mais adiante em um romance. Justamente foi o que ocorreu: o aproveitamento das "crônicas" na ficção ou da ficção nas "crônicas" claricianas, caracterizando um trânsito livre de textos, um intercâmbio de formas e gêneros. Para não corrermos o risco de nos afastarmos da realidade dos fatos, podemos, então, caracterizar a produção textual de Clarice Lispector veiculada no $J B$ como experiências de vida, respirações do mundo, pensamentos.

Se representavam, de fato, anotações para romances ainda inéditos da autora, já guardavam, segundo a diferenciação proposta por Wolfgang Iser (1996), espaços para a intervenção do leitor. Estabelecendo uma diferença entre a interação diádica e o que acontece no texto literário, o teórico assinala como os vazios demandam efetivamente o leitor muito mais intensamente no segundo caso. Se por um lado, a interação diática acontece "face a face", num diálogo onde é possível obter um feed-back direto com o autor - como num telefonema, numa conversa, num email - o mesmo não acontece no texto literário, onde o leitor não tem meios de checar suas interpretações com o autor, e mesmo que o tivesse, seria inútil. O fundamental para Iser é a diferença entre determinado e 
indeterminado. Importa a falta de precisão que diferencia o texto literário do não literário. Os vazios deste último são transformados em continuidade sem esforços maiores - ou no dizer de Roland Barthes (1992), os textos lidos se tornam escrevíveis.

Poderiam alguns objetar dizendo que os textos publicados no Jornal do Brasil são o relato de acontecimentos diários, que de uma forma ou de outra marcaram a vida da autora. Mesmo neste caso, não se tratavam de textos lineares, descritivos, documentais, já que entremeavam elementos de ficção, fantasia e reflexão, hesitação, além de não se proporem como textos meramente informativos.

Aqui, convém destacar as oportunas considerações, nesta abordagem dos textos de Clarice, de Wilson Martins (2003), no texto "Folhetins: Machado e José de Alencar, observadores críticos e realistas". Para o autor, importa diferenciar o folhetim oitocentista do que hoje conhecemos como crônica, pelo modelo Rubem Braga ou Fernando Sabino:

Esta última é uma espécie literária que só tem de jornalístico o fato todo circunstancial de aparecer em periódicos. Ofolhetim, de seu lado, é parte integrante e específica do jornalismo, é a "revista" hebdomadária, ou seja, cotidiana, inseparável da atualidade e acontecimentos correspondentes. Alencar definiu-o muito bem como "a história da semana", confirmando o que Machado de Assis escrevera desde 1859 ao referir-lhe as origens históricas (em jornais franceses) e na natureza peripecial, inseparável da realidade exterior (MARTINS, 2003, p. 4).

A partir desta distinção, podemos entender como quase-crônicas os textos publicados no $\mathrm{JB}$, pois são textos literários, muitas vezes só distintos dos publicados na forma fragmentária do romance, por exemplo, porque apareciam como um episódio completo no periódico. Remontamos, quanto a este aspecto, à trajetória percorrida por Margarida de Souza Neves (1992), no texto "Uma escrita do tempo: memória, ordem e progresso nas crônicas cariocas", do livro A crônica: o gênero, sua fixação e suas transformações no Brasil. Referindo-se à passagem do século XIX ao século $\mathrm{XX}$, a autora destaca as crônicas cariocas produzidas neste período:

São muitas as invenções que povoam o cotidiano dos cariocas na virada do século XIX para o século XX. A crônica, na sua acepção moderna, é uma delas. Percorrer com os olhos da história, esses textos breves e saborosos que passam a ocupar na grande imprensa (outra das novidades do tempo) o espaço ocupado pelo folhetim constituise simultaneamente, um prazer e uma árdua tarefa. (NEVES, 1992, p. 77).

Quanto à imprensa carioca, na virada do século, a exemplo do que acontecia com a Cidade, modernizava-se, passando do aspecto artesanal dos diários a uma imprensa de cunho empresarial. Até mesmo Lima Barreto, encarado como voz descontente no conjunto dos contentes e empolgados com a nova ordem que se estabelecia no Rio de Janeiro daquela época, assimilou a importância da crônica na nova imprensa que surgia:

Mesmo quem não é diretor de um jornal parisiense e não está habituado à imprensa européia, pode, do pé para as mãos, indicar muitos (defeitos dos nossos jornais) ... isso de jornal 
sem folhetins, "sem crônicas", sem artigos, sem comentários, sem informações, sem curiosidades, não se compreende absolutamente. (NEVES, 1992: 81)

A citada relevância da crônica pode ser comprovada, ainda, pelo fato de terem dela lançado mão grandes intelectuais da época, assim como aqueles que pretendiam viver das letras. Foi justamente na virada do século que o gênero, sem perder seu caráter de narrativa e registro, incorporou uma qualidade moderna, qual seja, o lugar reconhecido à subjetividade do narrador. Se relacionarmos este último aspecto aos textos de Clarice para o JB, constataremos que eles se adequam à definição de crônica. Como explica Margarida de Souza Neves, trata-se, pela própria etimologia - chronus/ crônica - de um gênero colado ao tempo:

Num e noutro caso, a crônica guarda sempre de sua origem etimológica a relação profunda com o tempo vivido. De formas diferenciadas, porque diferente é em cada momento a percepção do tempo histórico, a crônica é sempre de alguma maneira o tempo feito texto, sempre e de formas diversas, uma escrita do tempo. (NEVES, 1992, p. 82)

Nos textos de Clarice Lispector, embora tomados pela subjetividade do narrador, existem alusões a fatos recentes: há muitas vezes uma certa contextualização. O texto "Estado de graça - trecho" (JB, 06.04.68), é um exemplo. A crônica trata, como indica o título, do "estado de graça", quando, segundo a autora, as pessoas são tomadas por uma lucidez que lhes permite até mesmo perceber nos outros a profunda beleza, antes imperceptível. Já na parte final, depois de fazer inúmeras afirmações a respeito deste "estado", Clarice diz que dele é possível sair-se melhor criatura do que se entrou. Termina o texto com uma pequena observação a respeito da situação dos estudantes do Brasil naquele momento, aproveitando como uma espécie de "deixa" suas últimas afirmações, sobre a possibilidade de sair-se do estado de graça com uma certa confiança no sofrimento e em seus caminhos:

Experimentou-se alguma coisa que parece redimir a condição humana, embora ao mesmo tempo fiquem acentuados os estreitos limites desta condição. E exatamente porque depois da graça a condição humana se revela na sua pobreza implorante, aprende-se a amar mais, a perdoar mais, a esperar mais. Passa-se a ter uma espécie de confiança no sofrimento e em seus caminhos tantas vezes intoleráveis.

Há dias que são tão áridos e desérticos que eu daria anos de minha vida em troca de uns minutos de graça.

PS: - Estou solidária, de corpo e alma, com a tragédia dos estudantes do Brasil. (LISPECTOR, 1999, p. 93)

Representa, esta sentença final, praticamente a diferença mais marcante entre este material, publicado no jornal, e seu aproveitamento em Uma aprendizagem ou O livro dos prazeres. No romance, cinco páginas descrevem o "estado de graça" da personagem Lóri, o que obviamente foi omitido na crônica, passando a ser Clarice a narrar as sensações deste "estado especial". Depois de observar uma maçã sobre 
a mesa e de dar-lhe uma mordida, Lóri percebe estar acontecendo alguma coisa estranha:

Só deu uma mordida e depositou a maçã na mesa. Porque alguma coisa desconhecida estava suavemente acontecendo. Era o começo-de um estado de graça. (Lispector, 1993:154).

A escrita dos últimos anos de Clarice Lispector e a relação que ela estabeleceu com os leitores, expressa na coluna do $J B$, permite entender a sua "divisão" enquanto autora: aquela apegada, colada ao mundo concreto dos homens; e uma outra, misteriosa e enigmática, desejosa de viver todos os dilemas, de lançar-se nos mais perigosos mergulhos e abismos.

Voltando à grande receptividade dos textos claricianos em jornal e revistas, ela nos remete às reflexões de Walter Benjamin (1985) sobre o declínio da experiência ocorrido na modernidade e a oposição experiência/vivência. No caso da mídia impressa brasileira, desde as primeiras décadas do século XX, com o desenvolvimento dos jornais de tiragens cada vez maiores, até os dias de hoje, passando pelas decisivas inovações tecnológicas do meio (informatização das redações, construção dos modernos parques gráficos), é cativo, podemos dizer que fidelizado mesmo, o público leitor das colunas, dos espaços igualmente “cativos". Público - mesmo que cada vez mais reduzido - que, no tempo apressado da vida cotidiana, encontra no diálogo e intercâmbio com os mais diversos autores uma forma de compensação para o declínio da experiência enquanto partilha coletiva de memória e palavra comuns, conseqüência da vivência hostil da era da grande indústria.
Esta perda da experiência constitui o tema central de "Experiência e pobreza", escrito em 1933, e também apresenta-se para Walter Benjamin como um dos motivos da raridade moderna da figura do narrador, o que ele expôs em "O narrador", escrito entre 1928 e 1935. Os dois ensaios partem do que Benjamin denominou de perda ou declínio da experiência (Verfall der Erfahrung), ou seja, da experiência que repousa sobre a possibilidade de uma tradição compartilhada por uma determinada comunidade, retomada e transformada a cada geração, na continuidade das palavras transmitidas de pai para filho. Esta perda, por sua vez, acarreta o desaparecimento das formas tradicionais de narrativa, que têm sua origem na memória comum e na transmissibilidade:

Torna-se cada vez mais raro o encontro com pessoas que sabem narrar alguma coisa direito. É cada vez mais freqüente espalhar-se em volta o embaraço quando se anuncia o desejo de ouvir uma história. É como se uma faculdade, que nos parecia inalienável, a mais garantida entre as coisas seguras, nos fosse retirada. Ou seja: a de trocar experiências.

Uma causa deste fenômeno é evidente: a experiência caiu na cotação. E a impressão é a de que prosseguirá na queda intermi-nável. (BENJAMIN, 1985, p. 57).

No ensaio "O narrador" - onde Benjamin esboça a idéia de uma outra narração, uma narração nas ruínas da narrativa - são vários os trechos em que ele ressalta como ameaçadora a influência da informação no destino histórico da 
narrativa. Ao expor as condições que levaram à substituição da narrativa por outras formas de comunicação, ele identifica determinados elementos que, relacionados ao declínio da experiência, seriam característicos da existência dos homens modernos. Segundo o autor, na própria natureza da narrativa, existia uma dimensão utilitária, mesmo que de forma latente. Isto porque o narrador representava aquele homem que aconselhava, dispunha de sabedoria, estando, conseqüentemente, seu desaparecimento relacionado à morte da sabedoria em nosso meio. Assim, cada pessoa seria incapaz de narrar sua própria história. Para Benjamin, o homem teria perdido a capacidade de ouvir e transmitir histórias.

Nesse contexto, seria condição essencial para a sobrevivência da narrativa a retransmissão da história narrada pelo ouvinte, sendo que ela apresentaria qualidades que facilitariam sua manutenção pela memória. De acordo com Benjamin, a narrativa é destituída de análise psicológica, própria do romance, e de explicações, que definem as informações. Neste ponto, o autor proclama uma concorrência histórica entre as várias formas de comunicação, focando na pior situação a narrativa. Esta perde lugar e vez para o romance e a informação. Aqui, convém frisar que, se a existência da narrativa está ligada ao aconselhamento, dependendo de sua conservação na memória do ouvinte, sua substituição - pelo romance e pela informação - coincide com o esgarçamento dessas faculdades.

Bastante distante da narrativa, assim como o romance, está a informação, que se desenvolveu no capitalismo avançado, se constituindo em importante instrumento de dominação da burguesia. A partir destas considerações, podemos entender como a obra de Clarice Lispector (e, mais especificamente, seus textos escritos para jornal) refletia essa crise trazida pela modernidade. Afinal, o que a autora escrevia para a mídia impressa, ao mesmo tempo que não poderia ser caracterizado como ficção no sentido dos romances, estava distante da informação, da atividade jornalística de comunicar determinado fato, por meio das práticas básicas de objetivação, coerência e coesão.

Retornando à experiência de Clarice no $J B$ e à possível classificação dos textos produzidos neste período, surge a indagação: por que uma escritora como Clarice, considerada por muitos de difícil leitura, hermética, enveredou por textos "quase crônicas", uma forma mais despretensiosa de atingir o leitor? Talvez, porque o espaço reservado à crônica, com sua informalidade, impregnasse de possível leveza a linguagem densa da autora, que perscrutava o mistério das coisas mais simples. Compartilhando as idéias de Sylvia Paixão, em "Um sopro de vida na hora da estrela: uma leitura das crônicas de Clarice Lispector", artigo publicado na Revista Tempo Brasileiro, o mistério da escrita que envolve o leitor nos contos e nos romances vai sendo revelado nos textos publicados na imprensa:

Se nos contos e nos romances o
mistério de uma escrita envolve
o leitor num processo quase que
iniciático, nas crônicas este
mistério vai aos poucos sendo
desvendado, revelando o mundo
pessoal e subjetivo dessa autora
enigmática que se dirige ao
leitor informalmente, livre do
compromisso de conduzi-lo ao
espaço do sonho e da fantasia.
(PAIXÃO, 1991, p. 112).

Se nos contos e nos romances o iniciático, nas crônicas este mistério vai aos poucos sendo desvendado, revelando o mundo pessoal e subjetivo dessa autora enigmática que se dirige ao leitor informalmente, livre do (PAIXÃO, 1991, p. 112) 
$\mathrm{Na}$ conversa sem compromisso, leve e solta que estabeleceu com seus leitores, Clarice empreendeu esforços no sentido de deixar de lado qualquer artifício que pudesse afastá-la do seu público. Por isso, procurou lançar mão de uma linguagem mais leve como caminho para transmitir o seu mundo pessoal de experiências. Quando aceitou o convite para escrever no $J B$, sabia que passaria a se comprometer pessoalmente com o seu público leitor. O mesmo não acontecia enquanto atuava apenas como romancista ou contista, pois habitava e transitava pelo mundo da ficção assumida.

Como a própria crônica representa um texto, em geral, difícil de ser definido, já que pode se confundir com o conto, com a confissão íntima, ou até um texto satírico, Clarice, em várias situações, declarou sua dúvida entre estar ou não escrevendo este gênero. Como no texto "Ser cronista" (JB, 22.06.68):

Sei que não sou, mas tenho meditado ligeiramente no assunto. Na verdade eu deveria conversar a respeito com Rubem Braga, que foi o inventor da crônica. Mas quero ver se consigo tatear sozinha no assunto e ver se chego a entender. Crônica é um relato? É uma conversa? É o resumo de um estado de espírito? (LISPECTOR, 1999, p. 112)

O sentido histórico que acompanhou o termo - como registro de eventos passados - foi desaparecendo. A crônica passou a ser considerada "gênero menor", simples comentário de fatos do diaa-dia, fatos efêmeros, passageiros, para, com o tempo, a partir de sua relação com a imprensa, se trans- formar em sessão de jornal ou revista, e por conseqüência, espelho da vida moderna, rápida, fugaz, descosida. E é justamente desta sua aparente fragilidade que a crônica retira sua força, na obra de Clarice.

Em outros termos, na atribulada rotina da vida moderna, onde impera a pressa, ela representa uma forma de leitura marcada pela força poética e, muitas vezes, pelo humor, mais acessível: pode ser lida em qualquer lugar e por uma parcela da população que não costuma ter acesso aos livros, mas não são muitos os que buscam este espaço de leitura na mídia impressa.

Diante do que foi exposto, percebe-se que a crônica é o gênero adequado ao contador de casos, como Clarice Lispector. Com isso, ocorre uma certa recuperação da arte de narrar, que foi desaparecendo ao longo dos séculos, conforme Walter Benjamin:

Na era da informação, nada mais há para contar, tudo já foi veiculado pelos meios de comunicação. $O$ viajante não encontra mais ouvinte para suas novidades de países exóticos, pois todos já foram visitados pela indiscreta câmera dos telejornais. O narrador emudece diante da informação que é dada veloz-mente através de aparelhos cada vez mais aperfeiçoados e sofisticados. (BENJAMIN, 1985, p. 115).

Assim, como contadora de casos que seu olhar atento apreendia no diaa-dia, Clarice imprimiu cor e sentido novos a situações e pessoas. Não foi por acaso, portanto, que se aproximou e fascinou os leitores. A partir desta aproximação, começou a perceber a si própria, refletida no outro, no leitor. Quase sempre escritas em primeira pessoa, estas 
crônicas, relacionando o eu com o mundo, revelaram uma pessoa participando efetivamente do mundo ao seu redor.

A investigação do arejamento dos textos de Clarice Lispector publicados na mídia impressa implica na caracterização do jornalismo cultural. Capazes de estabelecer um vínculo afetivo com o leitor, que passa a dialogar com os colunistas, os suplementos e cadernos culturais dos veículos impressos sempre representaram o espaço da ousadia gráfica e da experimentação da linguagem. Embora nas duas últimas décadas tenham se afastado destas características, considerando-se que a cultura está cada vez mais inserida na sociedade do espetáculo, do consumo imediato, da superficialidade das abordagens, os cadernos culturais, na maioria das vezes, estiveram ligados à difusão da cultura consagrada e em processo de consagração.

\section{Abstract}

The object of study of this work are the texts of Clarice Lispector produced for the Carderno B of the Jornal do Brasil, in the period from 1967 to 1973 , and aeration undeniable that they have acquired to be published in printed media, allowing the author closer alignment with its public reader. Moreover, even those that were not readers of his book, considered by many of difficult access, could exchange experiences with the author, from texts that in the journalistic space, and soon earned in objectivity, characteristics that make it easier to read by readers of newspapers.

Keywords: Jornal do Brasil, chronicles, Clarice Lispector.

\section{Referências}

BARTHES, Roland. O prazer do texto. Tradução J. Guinsburg. São Paulo: Perspectiva, 2002. . S/Z. Tradução Léa Novaes. Rio: Nova Fronteira, 1992.
BENIAMIN, Walter. "Sobre o conceito da história". In: Obras escolhidas, v. I, Magia e técnica, arte e política. Tradução Sérgio Paulo Rouanet. São Paulo: Brasiliense, 1985.

"0 Narrador". Considerações sobre a obra de Nikolai Leskov". In: Obras escolhidas, v. I, Magia e técnica, arte e política. Trad. Sérgio Paulo Rouanet. São Paulo: Brasiliense, 1985.

COLASANTI, Marina. "Por que nos perguntam se existimos". In: Leitura: um cons/certo. Org. Norma Sandra de Almeida Ferreira. São Paulo: Companhia Editora Nacional, 2003.

ECO, Umberto. Lector in fábula. São Paulo: Perspectiva, 1979

FERREIRA, Theresa Cristina Montero. Correspondências. Rio de Janeiro: Rocco, 2002. Eu sou uma pergunta. Rio de Janeiro: Rocco, 1999

GOTLIB, Nádia Batella. Três vezes Clarice. São Paulo: Papéis Avulsos, 1989.

GURGEL, Gabriela Lírio. A procura da palavra no escuro:uma análise da criação de uma linguagem na obra de Clarice Lispector. Rio de Janeiro: 7 Letras, 2002

IANNACE, Ricardo. Aleitora Clarice Lispector. São Paulo: EDUSP, 2001

ISER, Wolfgang. "0 repertório do texto". In: 0 ato da leitura, vol. 1 , trad. Johannes Kretschner. São Paulo: Ed. 34, 1996.

. The implied reader. Baltimore:

Johns Hopkins University Press, 1974.

JAUSS, Hans Robert. A literatura e o leitor:textos de Estética da Recepção. Seleção, coordenação e tradução de Luiz Costa Lima. Rio de Janeiro: Paz e Terra, 1979.

LISPECTOR, Clarice. Uma aprendizagem ou Olivro dos prazeres. Rio de Janeiro: Francisco Alves, 1993. 
A descoberta do mundo. Rio de Janeiro: Rocco, 1999.

MANZO, Lícia. Era uma vez: eu: a não ficção na obra de Clarice Lispector. Juiz de Fora: Editora UFJF, 2001.

MARTINS, Wilson. "Folhetins: Machado e José de Alencar, observadores críticos e realistas". 0 Globo, Rio de Janeiro, 13 set. 2003. Prosa e Verso, p.4.

MEDEL, Manuel Ángel. Discurso literário e discurso jornalístico: convergências e divergências. In: Jornalismo eliteratura: a sedução da palavra. Org. Gustavo de Castro e Alex Galeno. São Paulo: Escrituras Editora, 2002.

NEVES, Margarida de Souza. "Uma escrita do tempo: memória, ordem e progresso nas crônicas cariocas". In: A crônica: o gênero, sua fixação e suas transformações no Brasil, organização: Setor Filologia FCRB. Campinas, SP: Ed. da Unicamp; Rio de Janeiro: Fundação Casa de Rui Barbosa, 1992.

OLINTO, Krieger Heidrun. "Literatura, cultura e ficções reais". In: Literatura e cultura. Org. Heidrun Krieger Olinto e Kart Eric Schollhammer. Rio de Janeiro: Ed. PUC-Rio; Sao Paulo: Loyola, 2003.

OTTEN, M. La lecture comme reconnaissance. Français 2000, n.104, fév. 1982.

PAIXÃO, Sylvia. "Um Sopro de Vida na Hora da Estrela; Uma Leitura das Crônicas de Clarice Lispector". In: Revista Tempo Brasileiro. Rio de Janeiro, 104: p.111-120, jan/mar. 1991.

PICARD, Michel. La lecture comme jeu. Paris: Minuit, 1986. 